\title{
Carnosine: A Possible Drug for Vascular Dementia
}

Dai Mizuno* and Masahiro Kawahara

Department of Bio Analytical Chemistry, Research Institute of Pharmaceutical Sciences, Musashino University, Tokyo, Japan

*Corresponding author: Dai Mizuno, Department of Bio Analytical Chemistry, Research Institute of Pharmaceutical Sciences, Musashino University, Nishitokyo-shi, Tokyo, 202-8585, Japan, Tel/Fax: +81-424-689-335; E-mail: d_mizuno@musashino-u.ac.jp

Rec date: Jul 16, 2014, Acc date: Aug 11, 2014, Pub date: Aug 13, 2014

Copyright: $\odot 2014$ Dai Mizuno, et al. This is an open-access article distributed under the terms of the Creative Commons Attribution License, which permits unrestricted use, distribution, and reproduction in any medium, provided the original author and source are credited.

\begin{abstract}
Carnosine ( $\beta$-alanyl histidine) is a small dipeptide with numerous beneficial effects, including the maintenance of the acid-base balance, antioxidant, chelating, anti-crosslinking, and anti-glycation activities in the living organism. High levels of carnosine are found in the skeletal muscles and in the brain. We have found that carnosine inhibits $\mathrm{Zn} 2+-$ induced neuronal death, which plays acrucial role in the pathogenesis of vascular dementia. Our previous research demonstrated that carnosine participates in the Endoplasmic Reticulum (ER)-stress pathway in Zninduced neurotoxicity and we have applied for a patent related to drugs for Vascular Dementia (VD). Here, we review the roles of carnosine in VD and otherneuro degenerative diseases and discuss perspectives about the future therapeutic use ofthis dipeptide.
\end{abstract}

Keywords: Carnosine; Vascular-type dementia; ZincAbbreviations: AßP: Amyloid $ß$ Protein; AD: Alzheimer's Disease; AGE: Advanced Glycation End-Product; AMPA: Amino-3-Hydroxy-5-Methyl-4Isoxazolepropionicacid; Arc: Activity-Related Cytoskeleton Protein; BDNF: Brain-Derived Neurotrophic Factor; Ca: Calcium; EDTA: Ethylenediaminetetra Acetic Acid; GADD: Growth-Arrest DNA Damage; His: Histidine; MT: Metallothionein; NMDA: N-Methyl-DAspartate; VD: Vascular-Type Dementia; VGLG: Voltage-Gated Ca ${ }^{2+}$ Channels; Zn: Zinc; Znt: Zn Transporter

\section{Introduction}

Carnosine, which is composed of $\beta$-alanine and L-histidine (His), is synthesized by the enzyme carnosine synthase, in a reaction that also requires ATP. Carnosine and its related compounds, homocarnosine and anserine (Figure 1A), are found in birds, fish, and mammals, including humans [1-4]. Carnosine is synthesized by muscle cells, glial cells, and oligodendrocytes [5], and the biggest concentration is observed in skeletal muscle tissue, the stomach, the kidney, cardiac muscle, and the brain [6-8]. In the brain, carnosine accumulates in neurons in the olfactory bulbs and in glial cells in other areas. The structures of carnosine and its related compounds, and the possible roles of carnosine, are shown in Figure 1A. Carnosine reportedly has numerous beneficial characteristics, such as maintaining $\mathrm{pH}$ balance [1], anti-glycation [9], antioxidant [7], hydroxyl radical scavenger [10], and as a chelator of metal ions $[11,12]$ as shown in Figure $1 \mathrm{~B}$. Considering that these properties are related to aging and that the olfactory bulb which acts as a gateway to the external environment, carnosine is believed to act as an endogenous anti-aging or neuroprotective agent.

Kanayama et al. have shown that intranasal administered metal ions were transported from the nasal cavity to the olfactory bulb via the olfactory nerve pathway, and then, metal ions are received by other brain regions such as the hypothalamus and the hippocampus [13]. These influxes may lead to excessive accumulation of metal ions that cause a neuronal injury as described below. We have previously investigated the molecular mechanism of zinc-induced neuronal death. After transient ischemia condition, an excess amount of glutamate causes the calcium $(\mathrm{Ca})$ dyshomeostasis and induces neuronal death, which finally leads to the pathogenesis of a Vascular type of Dementia (VD). Increasing evidence suggests that zinc ( $\mathrm{Zn}$ ) which is released with glutamate, enhances the neurotoxicity of the latter and plays crucial roles in the pathogenesis of VD. During the search for protective substances against $\mathrm{Zn}$-induced neurotoxicity, we found that carnosine exhibits marked inhibitory effects on $\mathrm{Zn}$ induced neurotoxicity and proposed its use as a possible therapeutic agent for VD. The level of carnosine varies during development and is low in the aged animals [3]. Therefore, it is highly possible that carnosine protects against external toxins and acts as an endogenous protective substance against neuronal injury and aging. In this article, we review the newest findings about the properties of carnosine, based on our own and other previous studies, and discuss possible drugs for $\mathrm{VD}$ and other neurodegenerative diseases.

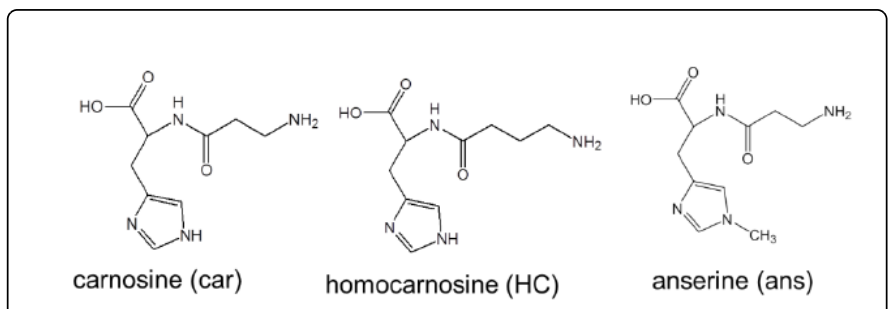

Figure 1A: Structures of carnosine and its related compound

\section{Expression and Distribution of Carnosine}

Carnosine contributes as much as $0.2-0.5 \%$ to the net weight of some muscles [14]. Studies performed on the gastrocnemius muscle showed that the concentration of carnosine in the human body is higher in males, decreases with age, and is dependent on diet (a vegetarian diet reduces the level of carnosine in skeletal muscle) $[15,16]$. In animals, factors such as trauma, shock, starvation, or injection negatively affect the level of carnosine in muscle tissue. 
Infection and trauma may be associated with cellular Ca dysregulation and myocardial depression. Carnosine administration may also play a role in the contractility of cardiac cells and the regulation of intracellular Ca levels [7].In the brain, carnosine is also present in the olfactory bulb [2]. We have developed a high-performance liquid chromatography system for analyzing and quantifying carnosine [17] and have confirmed that carnosine is abundant in the olfactory bulb in the rat brain. Biffo et al. also showed that carnosine is located in the olfactory receptor neurons, more specifically in the perikarya and cell processes, including the axons and synaptic terminals in the olfactory bulb [18]. Carnosine is rapidly formed and directed, via axoplasmic transport, to the olfactory bulb [19]. In the primary olfactory neurons, carnosine synthase activity is decreased upon denervation and is recovered upon regeneration [20,21]. The sensory neurons may be primarily responsible for the presence of carnosine in the olfactory bulb [3]. Carnosine and its related compounds are not degraded by regular dipeptidases, but are metabolized by specific hydrolytic enzymes, named carnosinases. The activity of carnosinase is very low shortly after birth and gradually increases to adult levels during adolescence, and attains higher levels in males than in females [15, 22]. Two types of carnosinases (CN1 and CN2) have been identified in humans and mice [4]. CN1 is highly present in human serum, but absent from non-primate mammals, except for the Syrian golden hamster [23]. Human CN1 is also expressed in the brain, liver, and kidney [4]. Most likely, these tissues are involved in the delivery of LHis or $\beta$-alanine. Recently, the gene for an enzyme, CN1 (EC3.4.13.20), which is expressed specifically in human brain, was characterized [24]. This enzyme may be involved in controlling the content of carnosine in the human brain. Under physiological conditions, the catalytic rate of $\mathrm{CN} 2$ is markedly lower than that of $\mathrm{CN} 1$. It remains to be determined whetherCN2 is involved in the degradation of carnosine in tissues that are abundant in carnosine.

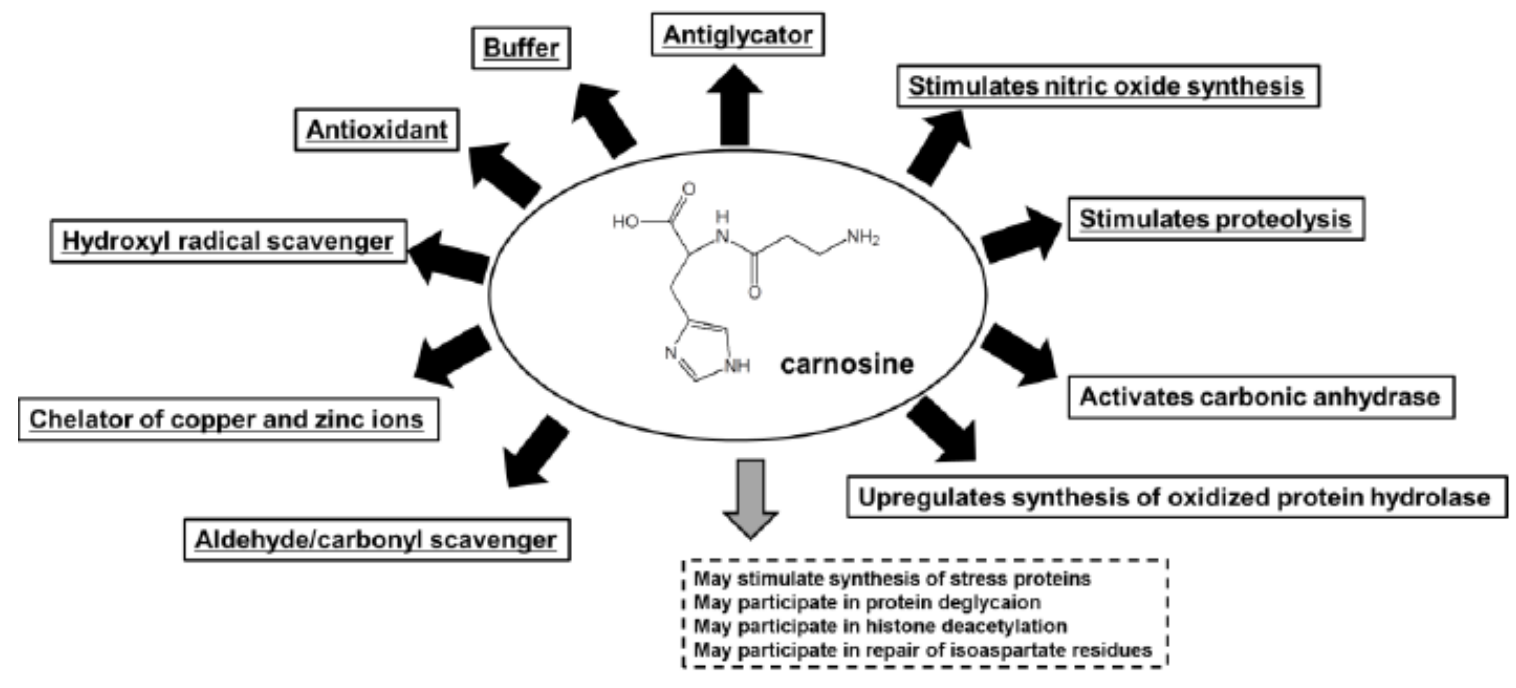

Figure 1B: Biological functions of carnosine

\section{Biological and Physiological Roles of Carnosine}

\section{Buffering activity}

Carnosine has many of possible biological functions, as shown in Figure 1B [25].The most convincing proposal is that carnosine plays one or more roles in the control of the intracellular hydrogen ion concentration $[1,26]$. During high-intensity anaerobic exercise, proton accumulation causes a decrease in intracellular $\mathrm{pH}$, which influences various metabolic functions. The $\mathrm{pKa}$ value of carnosine is 7.01, which is close to the intracellular $\mathrm{pH}$. Therefore, carnosine contributes to physicochemical non-bicarbonate buffering in skeletal muscles, and the administration of carnosine has been reported to induce hyperactivity in animals. This property may explain its predominant association with white, glycolytic, muscles which possess relatively few mitochondria and thereby generate lactic acid. These properties may help explain the protective action of carnosine in conditions associated with severe intracellular acidosis, such as ischemia.

\section{Metal ion-chelating activity}

Carnosine is a chelator of metal ions and forms complexes with $\mathrm{Ca}$, copper, and $\mathrm{Zn}$ ions $[11,12]$. Therefore, carnosine may exert some sort of control of Ca metabolism in muscle tissue (heart or skeletal). It is also likely that the dipeptide controls the availability of $\mathrm{Zn} 2+$ in neuronal tissue, particularly in the olfactory lobe where both carnosine and $\mathrm{Zn}$ are enriched [2,27,28]. Pharmacological $\mathrm{Zn}$-carnosine complexes are called polaprezinc and are also effective in the repair of ulcers and other lesions in the alimentary tract [29].

\section{Antioxidant activity}

When provided to humans as a supplement, carnosine has antioxidant properties, acting against free radicals, which contribute to aging in human. Carnosine scavenges both reactive oxygen and nitrogen, which contain unpaired electrons [30,31]. Carnosine may inhibit lipid oxidation through a combination of free radical scavenging and metal chelation. It also provides cells with an antioxidant system that functions in the cytosolic environment, where water soluble oxidation mediators are often present in high concentrations [7]. It has been demonstrated that oral ingestion of 


\section{(10.4172/2329-6925.1000146}

Page 3 of 7

carnosine for 3 months improves the overall appearance of skin and reduces the wrinkles that appear with age [32]. In mice, carnosine administration prolongs life expectancy and improves their c physical appearance and behavior [33].

\section{Carnosine in cardiovascular function}

Carnosine transiently decreases the systemic blood pressure in various mammalian species $[34,35]$, most likely by causing systemic arterial vasodilation. The direct vaso-relaxing effect of carnosine was demonstrated on isolated rat aortic rings [36]. This dipeptide may regulate the vascular tone. The in vivo formation of a $\mathrm{Zn} /$ carnosine complex and histamine $\mathrm{H} 1$ receptors appear to be involved in vascular smooth muscle contraction/relaxation [37]. Carnosine modulates $\mathrm{Ca}-$ regulated proteins in cardiac muscle cells, and can potentiate cardiac contractility [38]. In chemically skinned cardiac cells, carnosine releases $\mathrm{Ca}$, produces contracture, and alters the tension response of the contractile proteins to Ca. Carnosine also acts directly on the ryanodine receptor, a $\mathrm{Ca}-$ release channel, producing large increases in the open state probability and dwell time. A side from the modulation of intracellular $\mathrm{Ca}$, carnosine may play a role in $\mathrm{pH}$ regulation and may contribute to the mobile buffering system in cardiac cells [19].

\section{Carnosine in the sense organs}

Carnosine may affect the sense organs. The dipeptide can have a protective effect on retinal capillary cells. Oral administration of carnosine to rats that had remained hyperglycemic for 6 months reduced the blood vessels of the retina $[39,40]$. It has been shown that the use of eye drops containing $\mathrm{N}$-acetyl carnosine prevented development of cataracts and lens turbidity and contributed to prevention of the development of blurred vision and even blindness in the elderly [40]. Carnosine may also protect the hearing system. In rats, intraperitoneal injections of carnosine were shown to reduce the severity

\section{Carnosine in the brain}

A number of roles of carnosine in the brain have been proposed. On the basis of the high concentrations of carnosine found in olfactory neurons, this dipeptide was hypothesized to be involved in sensory neurotransmission, either as a neurotransmitter or a neuromodulator. Immunohistochemical studies have shown colocalization of carnosine and glutamate in the synaptic terminals of mouse olfactory bulbs [28]. As for most other sensory pathways, glutamate is the main excitatory neurotransmitter involved in the synapses between olfactory neurons and target cells (mitral and periglomerular cells) in the olfactory bulb. This supports the hypothesis of a role for carnosine in neuromodulation of glutamatergic sensory neurons.

\section{Carnosine as a Protective Substance against Neurotoxicity}

Carnosine inhibits the Maillard reaction that involves reduction of sugar and proteins, providing a multitude of end-products, most notably advanced glycation end-products (AGEs) [9]. AGEs can contribute to the pathogenesis of various senile diseases, such as Alzheimer's disease (AD), vascular stiffening, atherosclerosis, osteoarthritis, inflammatory arthritis, and cataracts [42]. Furthermore, carnosine is reported to have anti-crosslinking properties [43]. Carnosine has been reported to inhibit alpha-crystallin fibrillation [44]. It is widely recognized that crosslinking and conformational changes in disease-related proteins (e.g., amyloid $B$ protein (AßP), prion protein) are central to the pathogenesis of various neurodegenerative diseases, termed "conformational diseases", including $\mathrm{AD}$ and prion diseases $[45,46]$. We previously demonstrated that carnosine attenuates neuronal death induced by prion protein fragment peptide (PrP106-126), by changing its conformation [47]. It has also been demonstrated that carnosine inhibits the aggregation and subsequent neurotoxicity of AßP [48]. Corona et al. showed that dietary supplementation of carnosine attenuates the accumulation of AßP and mitochondrial dysfunction in Alzheimer's model mice [49]. Carnosine levels are also significantly reduced in the serum of $\mathrm{AD}$ patients [50]. These results suggest possible beneficial effects of carnosine as a treatment for $\mathrm{AD}$ and prion diseases. Analogues of carnosine, such as anserine or homocarnosine, may also prove to be useful owing to their similar antioxidant activities. Furthermore, as described below, we also demonstrated that carnosine inhibited $\mathrm{Zn} 2+-$ induced neuronal death, which is involved in the pathogenic mechanisms of VD [51].

\section{Carnosine as a Possible Therapeutic Agent for VascularType Dementia}

\section{Zinc induced neurodegeneration after Ischemia}

$\mathrm{VD}$ is a degenerative cerebrovascular disease, and its risk factors include age, male gender, diabetes, and high blood pressure. The most common type of VD is caused by a series of small strokes or ischemia [52]. Following transient global ischemia or stroke, the interruption of blood flow and the resulting oxygen-glucose deprivation induce longlasting membrane depolarization and an excessive release of glutamate into synaptic clefts. Thereafter, the excess glutamate causes an overstimulation of the relevant receptors, namely N-methyl-Daspartate (NMDA)-type receptors, amino-3-hydroxy-5-methyl-4isoxazolepropionic acid (AMPA)-type receptors, and kainate-type receptors. Finally, $\mathrm{Ca} 2+$ dyshomeostasis, which involves the entry of large quantities of $\mathrm{Ca} 2+$ into glutamate-responsive neurons, triggers the delayed death of vulnerable populations of neurons, such as pyramidal neurons in the hippocampus-an area associated with learning and memory. Thereafter, the development of an infarct and subsequent cognitive dysfunction mark the pathogenesis of VD in elderly people. Approximately $30 \%$ of stroke patients show symptoms of dementia within 3 months of the initial stroke [53]. Furthermore, chelatable $\mathrm{Zn}$ reportedly moves from presynaptic terminals into postsynaptic neuronal cell bodies. An increase in intracellular $\mathrm{Zn} 2+$ levels ([Zn2+]i), i.e., $\mathrm{Zn}$ translocation, occurs in vulnerable neurons in the CA1 or CA3 regions of the hippocampus prior to the onset of delayed neuronal death after transient global ischemia [50]. This $\mathrm{Zn}$ translocation has been reported to enhance the appearance of infarcts. Administration of Ca-ethylene diamine tetra acetic acid (Ca-EDTA), a membrane-impermeable chelator that chelates cations other than $\mathrm{Ca}$, has been shown to block the translocation of $\mathrm{Zn}$, protect hippocampal neurons after transient global ischemia, and reduce infarct volume [54]. Thus, $\mathrm{Zn}$ translocation has been recognized as the primary event in the pathway of $\mathrm{Zn}$-induced neuronal death. Sensi et al. have observed temporal changes in $[\mathrm{Zn} 2+] \mathrm{i}$ in cultured cortical neurons, using a $\mathrm{Zn}$-sensitive fluorescent dye; their results revealed at least 3 major routes for $\mathrm{Zn} 2+$ entry: voltage-gated $\mathrm{Ca} 2+$ channels (VGLG), NMDA-type glutamate receptors, and AMPA/kainate-type glutamate receptors $(\mathrm{A} / \mathrm{K}-\mathrm{R})$. Although the NMDA-type glutamate receptors are present in most neurons, the permeability of AMPA/ kainate channels for $\mathrm{Zn} 2+$ and $\mathrm{Ca} 2+$ is greater than that of NMDA- 
type glutamate receptor channels [55].Under normal conditions, most hippocampal neurons express AMPA receptors withGluR2 subunits, which are poorly permeable to divalent cations, including $\mathrm{Ca} 2+$ andZn2+ $(\mathrm{A} / \mathrm{K}-\mathrm{R})$. However, under ischemic conditions, there is an acute reduction in the expression of the GluR2 subunit, and neurons express specific types of AMPA receptors in which the channels are directly $\mathrm{Ca} 2+-$ permeable (Ca-AMPA/kainate channels; $\mathrm{Ca}-\mathrm{A} / \mathrm{K}-\mathrm{R}$ ) [56]. The appearance of $\mathrm{Ca}-\mathrm{A} / \mathrm{K}-\mathrm{R}$ causes increased $\mathrm{Ca} 2+$ permeability and enhances cytotoxicity. Therefore, the expression of $\mathrm{Zn} 2+-$ permeable $\mathrm{Ca}-\mathrm{A} / \mathrm{K}-\mathrm{R}$ and the entry of $\mathrm{Ca} 2+$ and/or $\mathrm{Zn} 2+$ through the channels are involved in delayed neuronal death after ischemia. Considering that Ca-EDTA, a Zn chelator, attenuates the ischemia-induced down regulation of the GluR2 gene [55], Zn has also been implicated in the transcriptional regulation of $\mathrm{Ca}-\mathrm{A} / \mathrm{K}-\mathrm{R}-$ encoding genes. These results strongly implicate $\mathrm{Zn}$ as a key player in delayed neuronal death after transient global ischemia, a process that may be involved in the pathogenesis of VD $[57,58]$. The accumulation of $\mathrm{Zn}$ has also been observed following head trauma and epilepsy [59], implying that $\mathrm{Zn}$ neurotoxicity may underlie the pathological mechanisms of various injuries. Moreover, the disruption of $\mathrm{Zn}$ homeostasis has also been implicated in other neurodegenerative diseases, including $\mathrm{AD}$ [60-62], prion disease [63], amyotrophic lateral sclerosis [64], and Wilson's disease [65]. Thus, Zn may play a role like that of Janus, the ancient Roman god of doorways who has 2 different faces, in the brain: both $\mathrm{Zn}$ depletion and excess $\mathrm{Zn}$ cause severe damage to neurons.

\section{Carnosine inhibits zinc-induced neurodegeneration}

Considering the implication of $\mathrm{Zn}$ in transient global ischemia, substances that protect against $\mathrm{Zn}$-induced neuronal death could be potential candidates for the prevention or treatment of neurodegeneration following ischemia and could ultimately provide a clue to treatments for VD. We examined the potential inhibitory effects of various agricultural products, such as vegetable extracts, fruit extracts, and fish extracts, and found that extracts from eel muscles significantly protected against $\mathrm{Zn}$-induced neurotoxicity [66]. Finally, we determined that carnosine, a small hydrophilic peptide abundant in eel muscles, protected GT1-7 cells from Zn-induced neurotoxicity in a dose-dependent manner (Figure 2). GT1-7 cells, which are immortalized hypothalamic neurons, are more vulnerable to $\mathrm{Zn}$ than other neuronal cells are $[67,68]$.

Zn causes the apoptotic death of GT1-7 cells in a dose-dependent and time-dependent manner. The cells possess neuronal characteristics, such as the extension of neurites and the secretionor the expression of several neuron-specific proteins or receptors. Additionally, GT1-7cells either lack, or possess low levels of, ionotropic glutamate receptors and do not exhibit glutamate toxicity [69]. These properties make the GT1-7 cell line an excellent model system for the investigation of $\mathrm{Zn}$-induced neurotoxicity. We recently suggested that $\mathrm{Ca}$ dyshomeostasis may be involved in the mechanisms underlying $\mathrm{Zn}$-induced neurotoxicity [51]. Zn-induced neuronal death revealed an upregulation of several genes, including metalrelated genes (metallothionein $(M T)-1, M T-2$, and the $\mathrm{Zn}$ transporter $1(Z n T-1)$ ), ER stress-related genes (growth-arrest DNA damage $(G A D D) 34, G A D D 45$, and $p 8$ ), and the $\mathrm{Ca}^{2+}$-related gene $\operatorname{Arc}$ (activity-related cytoskeleton protein) [70]. These findings are significant, given the involvement of $\mathrm{Ca}^{2+}$ homeostasis in $\mathrm{Zn}$-induced neurotoxicity. It is widely accepted that the $\mathrm{ER}^{2+} G A D D 34 G A D D 45 p 8$ Arc Arc

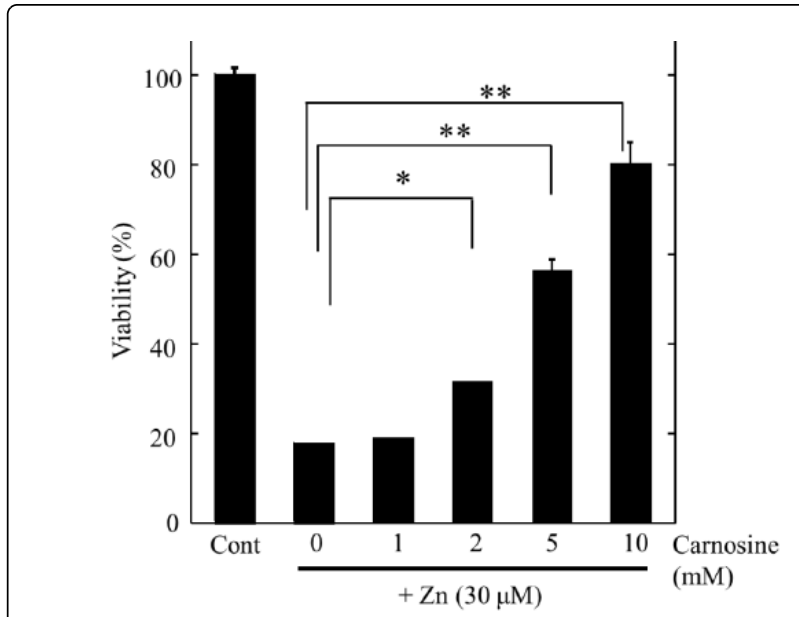

Figure 2: Carnosine protected GT1-7 cells from Zn induced neurotoxicity in a dose-dependent manner

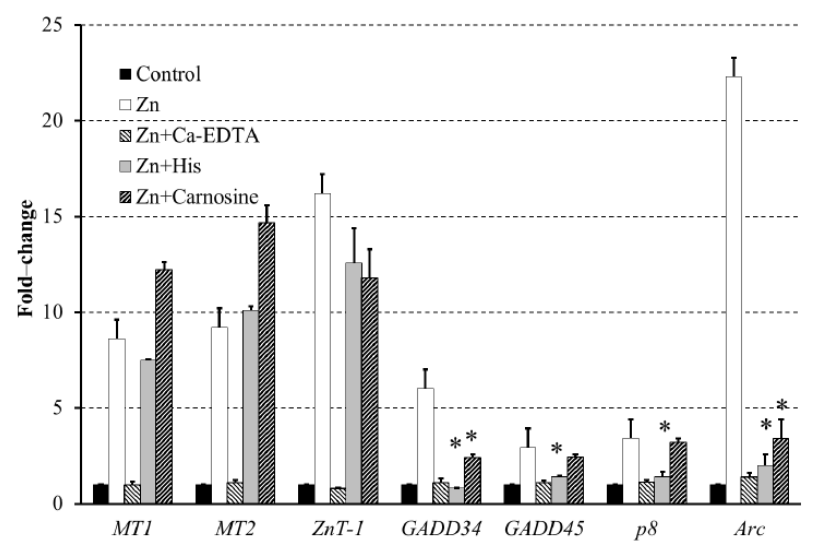

Figure 3: Existence of Ca-EDTA, His and Carnosine abolished the effects of $\mathrm{Zn}$

MT1, MT2, or ZnT-1GADD34, GADD45, p8Arc Arc

\section{Conclusion}

We have the relevance of carnosine as a possible therapeutic agent for VD. Carnosine, which is a naturally occurring dipeptide, is commonly present in vertebrate tissues, particularly within the skeletal muscles and nervous tissues [31]. It is found in high concentrations in the muscles of animals and fish with high levels of physical exertion, such as horses, chickens, and whales. Carnosine reportedly has various functions, including anti-oxidant, anti-glycation, and anticrosslinking functions, and it is considered to be an endogenous neuroprotective and anti-aging substance. Considering the advantageous properties of carnosine (relatively nontoxic, heat-stable, and water-soluble), dietary supplementation of carnosine may be an effective strategy for the prevention or treatment of neurodegenerative diseases, such as ischemia, $\mathrm{VD}, \mathrm{AD}$, and prion diseases. Corona et al. have reported that the supplementation of carnosine improved the learning abilities of Alzheimer's model mice [49]. We have demonstrated that the neurotoxicity of the prion protein fragment is 
Page 5 of 7

attenuated by $\mathrm{Zn}$ and carnosine [47]. Therefore, we have applied for patents for carnosine (application No.2006-145857; publication No. 2007-314467 in Japan) [77] and for His (application No.2008-098675; publication No. 2009-249335 in Japan) as drugs for the treatment of $\mathrm{VD}$ or for slowing the progress of cognitive decline after ischemia. Alimentary absorbed carnosine elevates the blood level of His via digestion in small intestinal cells [78].

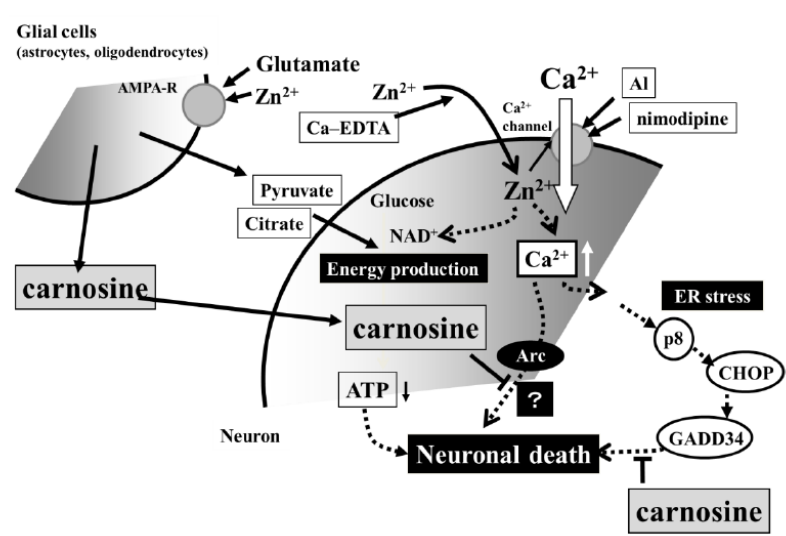

Figure 4: Flow chart for inhibition of apoptotic pathways that are activated by $\mathrm{Zn}$

The elevation in circulating levels of His raises the concentration of carnosine in the skeletal muscle $[79,80]$. Therefore, dietary intake of carnosine may accumulate carnosine in the body including the brain, and may be effective for the prevention of VD. Szcześniak et al. reported that conducted carnosine and anserine supplementation in the elderly brings promising effects on cognitive functioning of participants [81]. Carnosine may also be useful for the drugs for the treatment of established VD. However, further research into the role of $\mathrm{Zn}$ in neuronal injury and the significance of $\mathrm{Zn}$ and $\mathrm{Ca}$ homeostasis are need to the development of new treatments for VD. In the brain, carnosine is also present in the olfactory bulb. Although the physiological roles of carnosine in the olfactory bulb are still unclear, olfactory bulb neurons are less sensitive to damage after ischemia compared to hippocampal neurons, despite the accumulation of $\mathrm{Zn}$. Furthermore, carnosine levels have been shown to vary during development [3], and the content of carnosine in muscle is decreased in aged animals [82]. Therefore, carnosine may play protective roles in $\mathrm{Zn}$-induced neuro-degeneration after ischemia in the olfactory bulb. It is plausible that carnosine may be transported into cell bodies, where it can inhibit several apoptotic pathways that are activated by $\mathrm{Zn}$ (Figure 4). In conclusion, we hope that our approaches about carnosine may benefit the development of drugs for the treatment of $\mathrm{VD}$ and other neurodegenerative diseases.

\section{Acknowledgment}

This work was partially supported by a Grant-in Aid for Scientific Research from the Ministry of Education, Culture, Sports, Science and Technology of Japan and by a Grant from Cooperation for Innovative Technology and Advanced Research in Evolutional Area (CITY AREA) from the Miyazaki Prefectural Industrial Support Foundation.

\section{Conflicts of interest}

The authors declare no conflicts of interest.

\section{References}

1. Abe H (2000) Role of histidine-related compounds as intracellular proton buffering constituents in vertebrate muscle. Biochemistry (Mosc) 65: 757-765.

2. Bonfanti L, Peretto P, De Marchis S, Fasolo A (1999) Carnosine-related dipeptides in the mammalian brain. Prog Neurobiol 59: 333-353.

3. De Marchis S, Modena C, Peretto P, Migheli A, Margolis FL, et al. (2000) Carnosine-related dipeptides in neurons and glia. Biochemistry (Mosc) 65: 824-833.

4. Boldyrev AA, Aldini G, Derave W (2013) Physiology and pathophysiology of carnosine. Physiol Rev 93: 1803-1845.

5. Bauer K (2005) Carnosine and homocarnosine, the forgotten, enigmatic peptides of the brain. Neurochem Res 30: 1339-1345.

6. Hipkiss AR, Preston JE, Himsworth DT, Worthington VC, Keown M, et al. (1998) Pluripotent protective effects of carnosine, a naturally occurring dipeptide. Ann N Y Acad Sci 854: 37-53.

7. Gariballa AE, Sinclair AJ (2000) Carnosine: physiological properties and therapeutic potential. Age Ageing 29: 207-210.

8. Hill CA, Harris RC, Kim HJ, Harris BD, Sale C, et al. (2007) Influence of beta- alanine supplementation on skeletal muscle carnosine concentrations and high intensity cycling capacity. Amino Acids 32: 225233.

9. Chen Y, Ho CT (2002) Effects of carnosine on volatile generation from Maillard reaction of ribose and cysteine. J Agric Food Chem 50: 23722376.

10. Kang JH (2005) Protection by Carnosine and Homocarnosine against LDOPA-Fe(III)-Mediated DNA Cleavage. Bull Korean Chem Soc 26: 1251-1254

11. Baran EJ (2000) Metal complexes of carnosine. Biochemistry (Mosc) 65: 789-797.

12. Trombley PQ, Horning MS, Blakemore LJ (2000) Interactions between carnosine and zinc and copper: implications for neuromodulation and neuroprotection. Biochemistry (Mosc) 65: 807-816.

13. Kanayama Y, Enomoto S, Irie T, Amano R (2005) Axonal transport of rubidium and thallium in the olfactory nerve of mice. Nucl Med Biol 32: 505-512.

14. Bakardjiev A, Bauer K (2000) Biosynthesis, release, and uptake of carnosine in primary cultures. Biochemistry (Mosc) 65: 779-782.

15. Everaert I, Mooyaart A, Baguet A, Zutinic A, Baelde H, et al. (2011) Vegetarianism, female gender and increasing age, but not CNDP1 genotype, are associated with reduced muscle carnosine levels in humans. Amino Acids 40: 1221-1229.

16. Derave W, Everaert I, Beeckman S, Baguet A (2010) Muscle carnosine metabolism and beta-alanine supplementation in relation to exercise and training. Sports Med 40: 247-263.

17. Sadakane Y, Konoha K, Nagata T, Kawahara M (2007) Protective activity of the extracts from Japanese eel (Anguilla japonica) against zincinduced neuronal cell death: Carnosine and an unknown substance. Trace Nutr Res 24: 98-105.

18. Biffo S, Grillo M, Margolis FL (1990) Cellular localization of carnosinelike and anserine-like immunoreactivities in rodent and avian central nervous system. Neuroscience 35: 637-651.

19. Margolis FL, Grillo M (1977) Axoplasmic transport of carnosine ( $\beta-$ alanyl-L- histidine) in the mouse olfactory pathway. Neurochem Res 2 : 507-519.

20. Harding J, Graziadei PP, Monti Graziadei GA, Margolis FL (1977) Denervation in the primary olfactory pathway of mice. IV. Biochemical and morphological evidence for neuronal replacement following nerve section. Brain Res 132: 11-28. 
21. Harding J, Margolis FL (1976) Denervation in the primary olfactory pathway of mice. III. Effect on enzymes of carnosine metabolism. Brain Res 110: 351-360.

22. Peters V, Kebbewar M, Jansen EW, Jakobs C, Riedl E, et al. (2010) Relevance of allosteric conformations and homocarnosine concentration on carnosinase activity. Amino Acids 38: 1607-1615.

23. Jackson MC, Kucera CM, Lenney JF (1991) Purification and properties of human serum carnosinase. Clin Chim Acta 196: 193-205.

24. Teufel M, Saudek V, Ledig JP, Bernhardt A, Boular S, et al. (2003) Sequence identification and characterization of human carnosinase and a closely related non- specific dipeptidase. J Biol Chem 278: 6521-6531.

25. Quinn PJ, Boldyrev AA, Formazuyk VE (1992) Carnosine: its properties, functions and potential therapeutic applications. Mol Aspects Med 13: 379-444.

26. Vaughan-Jones RD, Spitzer KW, Swietach P (2006) Spatial aspects of intracellular $\mathrm{pH}$ regulation in heart muscle. Prog Biophys Mol Biol 90: 207-224.

27. Bakardjiev A (1997) Biosynthesis of carnosine in primary cultures of rat olfactory bulb. Neurosci Lett 227: 115-118.

28. Sassoè-Pognetto M, Cantino D, Panzanelli P, Verdun di Cantogno L, Giustetto M, et al. (1993) Presynaptic co-localization of carnosine and glutamate in olfactory neurones. Neuroreport 5: 7-10.

29. Matsukura T, Tanaka H (2000) Applicability of zinc complex of Lcarnosine for medical use. Biochemistry (Mosc) 65: 817-823.

30. Guney Y, Turkcu UO, Hicsonmez A, Andrieu MN, Guney HZ, et al. (2006) Carnosine may reduce lung injury caused by radiation therapy. Med Hypotheses 66: 957-959.

31. Hipkiss AR (2009) Carnosine and its possible roles in nutrition and health. Adv Food Nutr Res 57: 87-154.

32. Liu WH, Liu TC, Yin MC (2008) Beneficial effects of histidine and carnosine on ethanol-induced chronic liver injury. Food Chem Toxicol 46: 1503-1509.

33. Boldyrev AA, Gallant SC, Sukhich GT (1999) Carnosine, the protective, anti-aging peptide. Biosci Rep 19: 581-587.

34. Du Vigneaud V, Hunt M (1936) The synthesis of D-carnosine, the enantiomorph of the naturally occurring form, and a study of its depressor effect on the blood pressure. J Biol Chem 115: 93-100.

35. Niijima A, Okui T, Matsumura Y, Yamano T, Tsuruoka N, et al. (2002) Effects of L-carnosine on renal sympathetic nerve activity and DOCAsalt hypertension in rats. Auton Neurosci 97: 99-102.

36. Ririe DG, Roberts PR, Shouse MN, Zaloga GP (2000) Vasodilatory actions of the dietary peptide carnosine. Nutrition 16: 168-172.

37. Miller DJ, O'Dowd A (2000) Vascular smooth muscle actions of carnosine as its zinc complex are mediated by histamine $\mathrm{H}(1)$ and $\mathrm{H}(2)$ receptors. Biochemistry (Mosc) 65: 798-806.

38. Roberts PR, Zaloga GP (2000) Cardiovascular effects of carnosine. Biochemistry (Mosc) 65: 856-861.

39. Pfister F, Riedl E, Wang Q, vom Hagen F, Deinzer M, et al. (2011) Oral carnosine supplementation prevents vascular damage in experimental diabetic retinopathy. Cell Physiol Biochem 28: 125-136.

40. Babizhayev MA, Micans P, Guiotto A, Kasus-Jacobi A (2009) Nacetylcarnosine lubricant eyedrops possess all-inone universal antioxidant protective effects of $\mathrm{L}$-carnosine in aqueous and lipid membrane environments, aldehyde scavenging, and transglycation activities inherent to cataracts: a clinical study of the new vision- saving drug $\mathrm{N}$-acetylcarnosine eyedrop therapy in a database population of over 50,500 patients. Am J Ther 16: 517-533.

41. Zhuravskii SG, Aleksandrova LA, Ivanov SA, Sirot VS, Lopotko AI, et al. (2004) Protective effect of carnosine on excitable structures of the auditory apparatus in albino rats with acute acoustic trauma. Bull Exp Biol Med 137: 98-102.

42. Takeuchi M, Kikuchi S, Sasaki N, Suzuki T, Iwaki M, et al. (2004) Involvement of advanced glycation end-products (AGEs) in Alzheimer's disease. Curr Alzheimer Res 1: 39-46.
43. Hobart LJ, Seibel I, Yeargans GS, Seidler NW (2004) Anti-crosslinking properties of carnosine: significance of histidine. Life Sci 75: 1379-1389.

44. Attanasio F, Cataldo S, Fisichella S, Nicoletti S, Nicoletti VG, et al. (2009) Protective effects of L- and D-carnosine on alpha-crystallin amyloid fibril formation: implications for cataract disease. Biochemistry 48: 65226531.

45. Carrell RW, Lomas DA (1997) Conformational disease. Lancet 350: 134138.

46. Kawahara M, Ohtsuka I, Yokoyama S, Kato-Negishi M, Sadakane Y, et al. (2011) Membrane incorporation, channel formation, and disruption of calcium homeostasis by Alzheimer's $ß$-amyloid protein. Int J Alzheimer.

47. Kawahara M, Koyama H, Nagata T, Sadakane Y (2011) Zinc, copper, and carnosine attenuate neurotoxicity of prion fragment PrP106-126. Metallomics 3: 726-734.

48. Fernàndez-Busquets $\mathrm{X}$, Ponce $\mathrm{J}$, Bravo $\mathrm{R}$, Arimon $\mathrm{M}$, Martiáñez T, et al. (2010) Modulation of amyloid beta peptide(1-42) cytotoxicity and aggregation in vitro by glucose and chondroitin sulfate. Curr Alzheimer Res 7: 428-438.

49. Corona C, Frazzini V, Silvestri E, Lattanzio R, La Sorda R, et al. (2011) Effects of dietary supplementation of carnosine on mitochondrial dysfunction, amyloid pathology, and cognitive deficits in $3 \mathrm{xTg}-\mathrm{AD}$ mice. PLoS One 6.

50. Koh JY, Suh SW, Gwag BJ, He YY, Hsu CY, et al. (1996) The role of zinc in selective neuronal death after transient global cerebral ischemia. Science 272: 1013-1016.

51. Mizuno D, Kawahara M (2013) The involvement of endoplasmic reticulum-stress in zinc neurotoxicity and the pathogenesis of vascular type senile dementia. Int J Mol Sci 14: 22067-22081.

52. Lee JM, Grabb MC, Zipfel GJ, Choi DW (2000) Brain tissue responses to ischemia. J Clin Invest 106: 723-731.

53. De Haan EH, Nys GM, van Zandvoort MJ (2006) Cognitive function following stroke and vascular cognitive impairment. Curr Opin Neurol 19: 559-564.

54. Calderone A, Jover T, Mashiko T, Noh KM, Tanaka H, et al. (2004) Late calcium EDTA rescues hippocampal CA1 neurons from global ischemiainduced death. J Neurosci 24: 9903-9913.

55. Sensi SL, Canzoniero LM, Yu SP, Ying HS, Koh JY, et al. (1997) Measurement of intracellular free zinc in living cortical neurons: Routes of entry. J Neurosci 17: 9554-9564.

56. Pellegrini-Giampietro DE, Gorter JA, Bennett MV, Zukin RS (1997) The GluR2 (GluR-B) hypothesis: Ca2+-permeable AMPA receptors in neurological disorders. Trends Neurosci 20: 464-470.

57. Plum LM, Rink L, Haase H (2010) The essential toxin: Impact of zinc on human health. Int J Environ Res Public Health 7: 1342-1365.

58. Weiss JH, Sensi SL, Koh JY (2000) Zn2+: A novel ionic mediator of neural injury in brain disease. Trends Pharmacol Sci 21: 395-401.

59. Zhu L, Tang Y, Wang HD, Zhang ZY, Pan H (2012) Immersion autometallographic demonstration of pathological zinc accumulation in human acute neural diseases. Neurol Sci 33: 855-861.

60. Adlard PA, Bush AI (2006) Metals and Alzheimer's disease. J Alzheimers Dis 10: $145-163$.

61. Kawahara M, Arispe N, Kuroda Y, Rojas E (1997) Alzheimer's disease amyloid $\beta_{-}$- protein forms $\mathrm{Zn} 2+$-sensitive, cation-selective channels across excised membrane patches from hypothalamic neurons. Biophys J 73: 67-75.

62. Lin H, Bhatia R, Lal R (2001) Amyloid beta protein forms ion channels: Implications for Alzheimer's disease pathophysiology. FASEB J 15: 2433 2444.

63. Leach SP, Salman MD, Hamar D (2006) Trace elements and prion diseases: A review of the interactions of copper, manganese and zinc with the prion protein. Anim Health Res Rev 7: 97-105.

64. Valentine JS, Hart PJ (2003) Misfolded CuZnSOD and amyotrophic lateral sclerosis. Proc Natl Acad Sci USA 100: 3617-3622. 
Citation: Mizuno D, Kawahara M (2014) Carnosine: A Possible Drug for Vascular Dementia. J Vasc Med Surg 2: 146. doi:

65. Brewer GJ (2000) Recognition, diagnosis, and management of Wilson's disease. Proc Soc Exp Biol Med 223: 39-46.

66. Konoha K, Sadakane Y, Kawahara M (2006) Carnosine protects GT1-7 cells against zinc-induced neurotoxicity: A possible candidate for treatment for vascular type of dementia. Trace Nutr Res 23: 56-62.

67. Kawahara M, Kato-Negishi M, Kuroda Y (2002) Pyruvate blocks zincinduced neurotoxicity in immortalized hypothalamic neurons. Cell Mol Neurobiol 22: 87-93.

68. Koyama H, Konoha K, Sadakane Y, Ohkawara S, Kawahara M (2011) Zinc neurotoxicity and the pathogenesis of vascular-type dementia: Involvement of calcium dyshomeostasis and carnosine. J Clin Toxicol.

69. Mahesh VB, Zamorano P, De Sevilla L, Lewis D, Brann DW (1999) Characterization of ionotropic glutamate receptors in rat hypothalamus, pituitary and immortalized gonadotropin-releasing hormone (GnRH) neurons (GT1-7 cells). Neuroendocrinology 69: 397-407.

70. Kawahara M, Sadakane Y, Koyama H, Konoha K, Ohkawara S (2013) DHistidine and L-histidine attenuate zinc-induced neuronal death in GT1-7 cells. Metallomics 5: 453-460.

71. Brown MK, Naidoo N (2012) The endoplasmic reticulum stress response in aging and age-related diseases. Front Physiol 3: 263 .

72. Ferreiro E, Baldeiras I, Ferreira IL, Costa RO, Rego AC, et al. (2012) Mitochondrial- and endoplasmic reticulum-associated oxidative stress in Alzheimer's disease: From pathogenesis to biomarkers. Int J Cell Biol.

73. Roussel BD, Kruppa AJ, Miranda E, Crowther DC, Lomas DA, et al. (2013) Endoplasmic reticulum dysfunction in neurological disease. Lancet Neurol 12: 105-118.

74. Moskalev AA, Smit-McBride Z, Shaposhnikov MV, Plyusnina EN, Zhavoronkov A, et al. (2012) Gadd45 proteins: Relevance to aging, longevity and age-related pathologies. Ageing Res Rev 11: 51-66.
75. Van Prooyen N, Andresen V, Gold H, Bialuk I, Pise-Masison C, et al. (2010) Hijacking the T-cell communication network by the human Tcell leukemia/lymphoma virus type $1(\mathrm{HTLV}-1)$ p12 and p8 proteins. Mol Aspects Med 31: 333-343.

76. Goruppi S, Iovanna JL (2010) Stress-inducible protein p8 is involved in several physiological and pathological processes. J Biol Chem 285: 15771581.

77. Kawahara M, Konoha K, Nagata T, Sadakane Y (2007) Protective substances against zinc-induced neuronal death after ischemia: Carnosine a target for drug of vascular type of dementia. Recent Pat CNS Drug Discov 2: 145-149.

78. Gardner ML, Illingworth KM, Kelleher J, Wood D (1991) Intestinal absorption of the intact peptide carnosine in man, and comparison with intestinal permeability to lactulose. J Physiol 439: 411-422.

79. Maynard LM, Boissonneault GA, Chow CK, Bruckner GG (2001) High levels of dietary carnosine are associated with increased concentrations of carnosine and histidine in rat soleus muscle. J Nutr 131: 287-290.

80. Tamaki N, Funatsuka A, Fujimoto S, Hama T (1984) The utilization of carnosine in rats fed on a histidine-free diet and its effect on the levels of tissue histidine and carnosine. J Nutr Sci Vitaminol (Tokyo) 30: 541-551.

81. Szcześniak D, Budzeń S, Kopeć W, Rymaszewska J (2014) Anserine and carnosine supplementation in the elderly: Effects on cognitive functioning and physical capacity. Arch Gerontol Geriatr. in press.

82. Stuerenburg HJ (2000) The roles of carnosine in aging of skeletal muscle and in neuromuscular disease. Biochemistry (Mosc) 65: 862-865. 